\title{
Parametric Study of Printed Monopole Antenna Bioinspired on the Inga Marginata Leaves for UWB Applications
}

\author{
Josiel do Nascimento Cruz, Raimundo Carlos Silvério Freire, Alexandre Jean René Serres \\ Post-Graduation Programme in Electrical Engineering - COPELE, Federal University of Campina Grande, \\ Campina Grande, Paraíba, Brazil \\ E-mail: Josiel.cruz@ee.ufcg.edu.br,rcsfreire@dee.ufcg.edu.br, alexandreserres@dee.ufcg.edu.br \\ Leidiane Carolina Martins de Moura, Andrécia Pereira da Costa, Paulo Henrique da Fonseca Silva \\ Federal Institute of Education, Science and Technology of Paraíba, IFPB, João Pessoa, Paraíba, Brazil \\ E-mail: henrique@ifpb.edu.br
}

\begin{abstract}
A microstrip leaf-shaped printed monopole antenna bioinspired on the Inga marginata leaves is presented in this paper for UWB applications. A parametric study of the proposed antenna bioinspired geometry was conducted in order to verify their resonant properties. The antenna was designed with a rectangular slitted ground plane for impedance matching and fabricated on inexpensive glass fiber substrate and fed by a $50 \Omega$ microstrip line. Numerical and experimental results were obtained. The results show an impedance bandwidth superior to $10.26 \mathrm{GHz}$, greater than the bandwidth considered UWB (7.5 GHz). Antenna dimensions were optimized with the computer program Ansys Designer ${ }^{\circledR}$ used to simulate the electromagnetic behavior of the antennas by the method of moments.
\end{abstract}

Index Terms - Leaf-shaped antenna, printed monopole antenna, UWB applications.

\section{INTRODUCTION}

Wireless communication systems have become increasingly popular due to the diversity of services offered, requiring portable communication devices that operate in multiple frequency bands. To meet the requirements of different systems, the use of embedded antennas with small size, ease of integration, desired gain pattern, large bandwidth, among other features that come with the device miniaturization and low-cost manufacture. Therefore, it appears that the microstrip antennas are promising candidates to address these specific requirements, as well as to operate at different frequency bands. It can also be used in satellite communications, GPS (Global Positioning System), RFID (Radio Frequency Identification), among many others.

The study of microstrip antennas with models bioinspired on leaves (leaf-shaped antennas) has aroused the interest of researchers due to the good results. The leaf serves as a model because of its characteristics which are similar to the antennas with respect to the reception of electromagnetic waves, as the leaves act in the capture of sunlight for conversion into chemical energy. 
Among the research on antennas bioinspired on leaves, some works can be cited with operation in the UWB range (ultra-wideband), such as Neyestanak [1], consisting of the model of a flower of four petals built in microstrip showing good results for return loss in the $4.30-8.12 \mathrm{GHz}$ band, and the work presented in [2], which uses the Canadian maple-leaf model with bandwidth around $6 \mathrm{GHz}$. In recent research, an antenna bioinspired on sugarcane leaf for being used in fourth-generation mobile communication systems (4G LTE) [3] was designed.

UWB antennas are used in military, commercial, medical, radar and mobile communications applications [4]. Among other applications, you can use them with the function of replacing the telecommunications cables between electronic devices over short distances (around 10 meters), preferably indoors as offices and homes [5]. According to the Federal Communications Commission (FCC), this technology which is designed to work at $3.1 \mathrm{GHz}-10.6 \mathrm{GHz}$, has a fractional bandwidth greater than 20\% [6] and shares this frequency band with other services already established by regulatory agencies, without causing interference, such as: Wi-Fi (Wireless Fidelity) that uses the standard IEEE 802.11 family for WLAN devices, WiMAX (Workdwide Interoperability for Microwave Access) and ISM band.

The UWB systems assume greater noise immunity, low-cost equipment, low-power operation, among other advantages. Due to these characteristics, this technology stands out among the wireless communications systems alternatives for short distances, especially on the fourth generation (4G) of mobile communications [7].

This paper presents a parametric study of the monopole antenna printed on microstrip which is bioinspired on the Inga marginata leaf for applications in UWB systems. The antenna studied was numerically analyzed through the commercial program Ansys Designer® and experimentally analyzed with the N5230A network analyzer from Agilent Technologies.

\section{PRinted Monopole Antenna}

The printed monopole antennas (PMA) have as main features the compact size and a wide bandwidth, with different applications. In Fig. 1 shows the geometry of a rectangular printed monopole antenna. The dimensions for an initial design can be approximated by fractions of the guided wavelength $\left(\lambda_{g}\right)$ to the first resonance [8], wherein $W$ and $L$ are respectively the width and length of the radiating patch, $W_{P T}$ is the width of the antenna, $L_{P T}$ is the length of the truncated ground plane, $W_{L T}$ is the width of the transmission line, $g$ is the distance between the patch and the ground plane, $h$ is the thickness of the dielectric. The technique presented in [9] is used for a better impedance matching. This technique proposes a rectangular opening (slit) in the ground plan with $L_{S}$ and $W_{S}$ dimensions. 


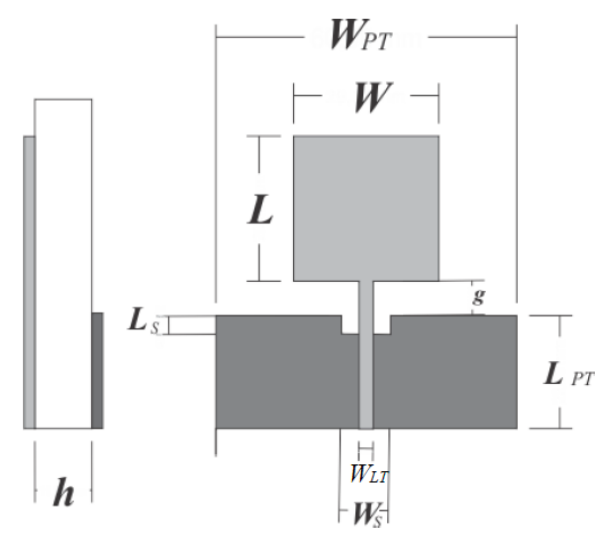

Fig. 1. Geometry of a rectangular printed monopole antenna [3].

The lowest frequency of PMA can be approximated by (1), where $p$ is the perimeter of the radiating patch and $\varepsilon_{r e f}$ is the effective relative permittivity of the dielectric [2].

$$
\begin{gathered}
f(G H z)=\frac{300}{p \sqrt{\varepsilon_{r e f}}} \\
\varepsilon_{r e f} \approx\left(\varepsilon_{r}+1\right) / 2
\end{gathered}
$$

The distribution of the electric current density in this antenna is concentrated mainly on the edges of the radiating patch. Thus, by increasing the perimeter $p$, there is a consequent increase on the wavelength, which, as a result, decreases the lowest resonance frequency [10].

\section{UWB ANTENNA BIOINSPIRED ON THE INGA MARGINATA LEAF}

The bioinspired motivation from which was developed the antenna design came from the observation of the arrangement of the leaves of a tropical plant, scientifically named Inga marginata Willd [11], see Fig. 2. Taking the PMA dimensions shown in Fig. 1 as reference, the radiating element of the bioinspired antenna is designed in the proposed leaf-shape.

Using ANSYS Designer® [13], the proposed leaf-shaped PMA was designed and simulated. Adjustments were made in the rectangular slit of the ground plane for obtaining the maximum impedance bandwidth, $\left|S_{11}\right|<-10 \mathrm{~dB}$.

Fig. 3 illustrates the geometry of the proposed leaf-shaped antenna. Values of antenna dimensions are listed in Table 1 for a glass fiber substrate (FR-4) with relative electric permittivity $\varepsilon_{\mathrm{r}}=4.4$, substrate height $h=1.5 \mathrm{~mm}$, and loss tangent $\delta=0.02$. The $50 \Omega$ microstrip feedline has a width of $2.87 \mathrm{~mm}$. An image of built leaf-shaped PMA prototype is shown in Fig. 4. 


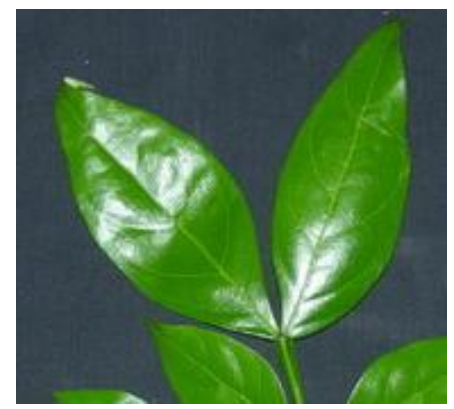

Fig. 2. Ingá marginata leaves [12].

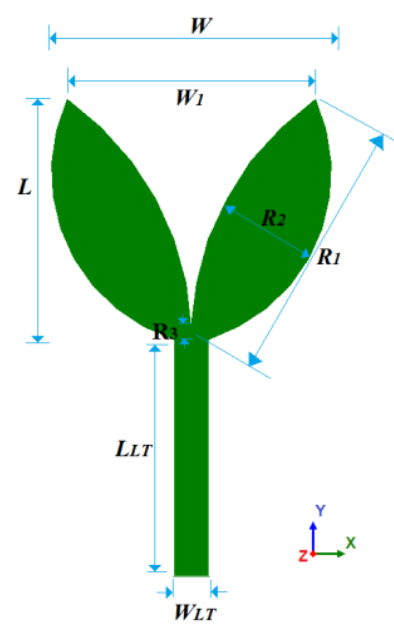

(a)

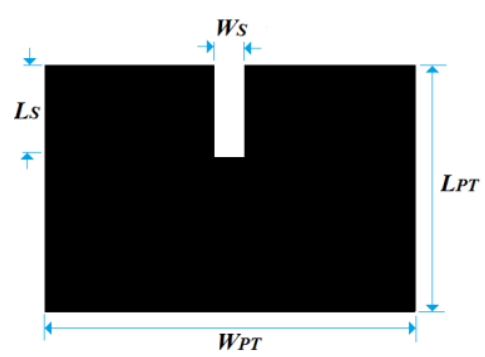

(b)

Fig.3. Proposed leaf-shaped PMA geometry: (a) leaf-shaped microstrip feedline and patch radiator (b) ground plane.

TABLE 1 - DESIGNED LEAF-SHAPED ANTENNA DIMENSIONS IN MILLIMETERS.

\begin{tabular}{cccccccccccc}
\hline $\boldsymbol{W}$ & $\boldsymbol{L}$ & $\boldsymbol{W}_{\boldsymbol{I}}$ & $\boldsymbol{W}_{\boldsymbol{L T}}$ & $\boldsymbol{L}_{\boldsymbol{L} \boldsymbol{T}}$ & $\boldsymbol{W}_{\boldsymbol{P} \boldsymbol{T}}$ & $\boldsymbol{L}_{\boldsymbol{P} \boldsymbol{T}}$ & $\boldsymbol{W}_{\boldsymbol{S}}$ & $\boldsymbol{L}_{\boldsymbol{S}}$ & $\boldsymbol{R}_{\boldsymbol{I}}$ & $\boldsymbol{R}_{\boldsymbol{2}}$ & $\boldsymbol{R}_{\boldsymbol{3}}$ \\
\hline 23.58 & 20 & 20.88 & 2.87 & 20 & 30 & 20 & 2.47 & 6 & 22 & 8.20 & 1 \\
\hline
\end{tabular}

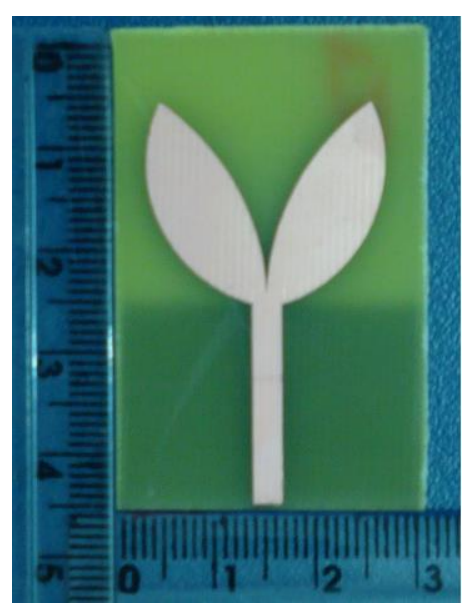

Fig. 4. Photograph of a built antenna prototype. 


\section{RESULTS AND DISCUSSIONS}

For a better understanding and characterization of the resonant behavior of the proposed bioinspired leaf-shaped PMA, a parametric analysis was performed for the return loss parameter $\left(R L=-20 \log \left|S_{11}\right| \mathrm{dB}\right)$ as a function of the main dimensions of the antenna. In particular, $W_{S}$ and $L_{S}$ dimensions were set for impedance matching purposes while the dimensions $R_{1}, R_{2}$ and $R_{3}$ were adjusted for tuning the antenna operating frequency band.

To obtain a better impedance matching in the UWB band, ground plane slit dimensions $\left(W_{S}, L_{S}\right)$ have been simulated in the ranges: $0.5<W_{S}<3.5 \mathrm{~mm}$, with step $1 \mathrm{~mm}$, and $2.0<L_{S}<10.0 \mathrm{~mm}$, with 2 $\mathrm{mm}$ step. The dimensions of $R_{1}, R_{2}$ and $R_{3}$ were considered in the simulations as shown in Table I.

Results for $L_{S}=6 \mathrm{~mm}$ and varying the dimension $W_{S}$ are shown in Fig. 5(a). Considering $\left|S_{11}\right|<-$ $10 \mathrm{~dB}$ impedance bandwidth, a $9-11 \mathrm{GHz}$ notch band is found to $W_{S}$ values of 2.5 and $3.5 \mathrm{~mm}$. From this parametric study, it was found that $1.5 \mathrm{~mm}$ is a great value for $W_{S}$, which results in better impedance matching. Fig. 5(b) shows the results for the reflection coefficient $\left(\left|S_{11}\right|\right.$ in $\left.\mathrm{dB}\right)$ varying the dimension $L_{S}$. It is noted a satisfactory impedance matching for all values of $L_{S}$, with $L_{S}=8 \mathrm{~mm}$ presenting the best result for the whole UWB band.

Considering the dimensions of the ground plane rectangular slit with $W_{\mathrm{S}}=1.5 \mathrm{~mm}$ and $L_{S}=8 \mathrm{~mm}$, the values of $R_{1}, R_{2}$ and $R_{3}$ varied in order to analyze the resonant behavior of the antenna bioinspired on the Inga marginata leaf. Fig. 6(a) shows the results obtained for the reflection coefficient considering $R_{l}$ ranging from $18 \mathrm{~mm}$ to $28 \mathrm{~mm}$ and $2 \mathrm{~mm}$ steps. With the increase of $R_{I}$ the perimeter of the radiating patch antenna also increases and therefore the first resonance frequency of the operating range is reduced. This behavior can be observed in Fig. 6(a), where, with the increase of 10 $\mathrm{mm}$ in $R_{l}$, a reduction of around $600 \mathrm{MHz}$ was obtained. It is also noticed that for the dimensions $R_{l}=$ $28 \mathrm{~mm}$ and $R_{l}=26 \mathrm{~mm}$ in the $7 \mathrm{GHz}$ to $8.3 \mathrm{GHz}$ band, the reflection coefficient is outside the $\mathrm{S} 11$ < 10 range. For other simulated values of $R_{l}$, a good impedance matching over the entire range and excellent bandwidth were obtained.

Fig. 6(b) shows the results for the return loss with different values of $R_{2}$. For values less than 6.2 $\mathrm{mm}$, the return loss at some points of the examined frequency band is above $-10 \mathrm{~dB}$. The results are satisfactory for all the other $R_{2}$ values.

Fig. 6(c) shows the results of the reflection coefficient for various values of $R_{3}$. There was little change in the resonant behavior of the antenna with the increase of $R_{3}$.

Measurements of the proposed antenna were obtained at GTEMA-IFPB (Group of Telecommunications and Applied Electromagnetism of the Federal Institute of Paraiba). A vector network analyzer, N5230A model from Agilent Technologies, with measuring range of $300 \mathrm{KHz}-$ 13.5 GHz was used.

Figs. 7 and 8 show simulated and measured results for the reflection coefficient and VSWR, respectively. The bandwidth set for a return loss less than $-10 \mathrm{~dB}$ presents a $2.74 \mathrm{GHz}-13 \mathrm{GHz}$ band 
of frequencies. In all measured range, the VSWR presents values below 2, indicating that the antenna has minimal reflections and the signal injected in it can be transmitted, what is a necessary condition for operations in UWB applications. These results are shown in Table 2. A bandwidth greater than the bandwidth considered UWB, which is $7.5 \mathrm{GHz}$, can be observed.

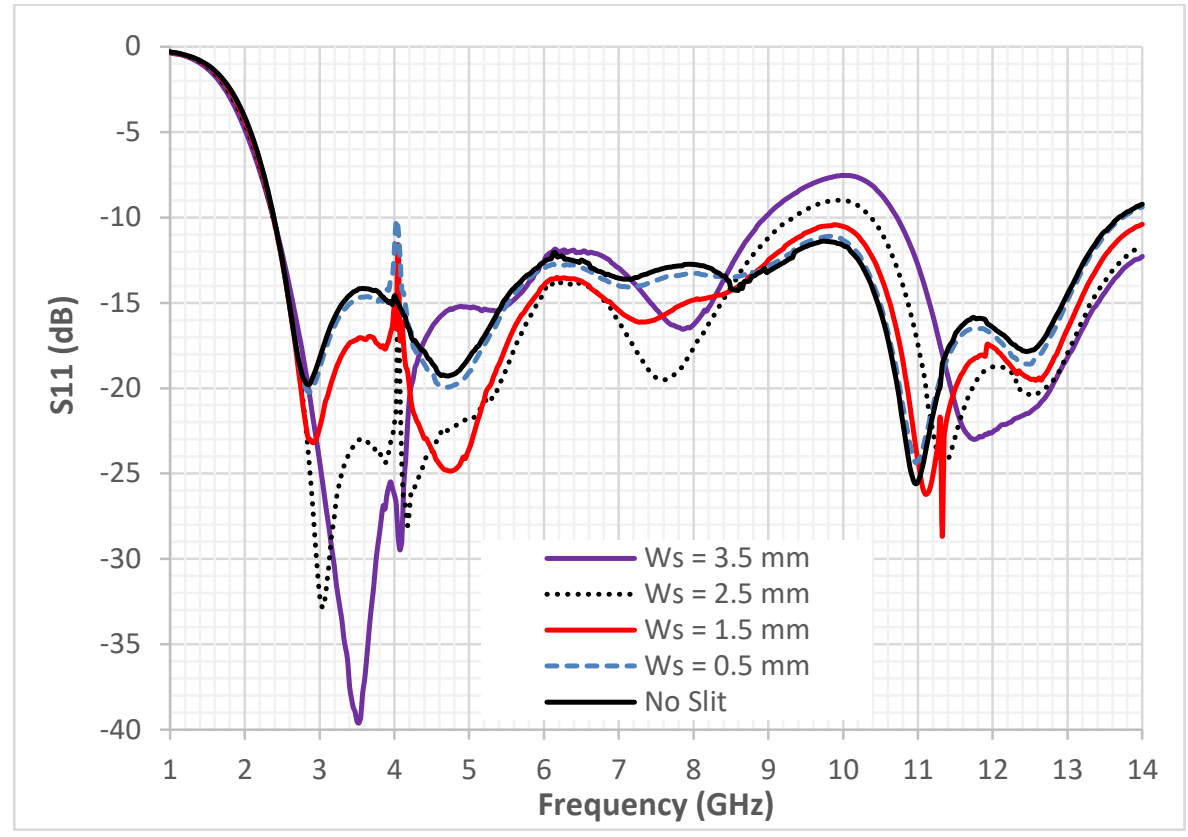

(a)

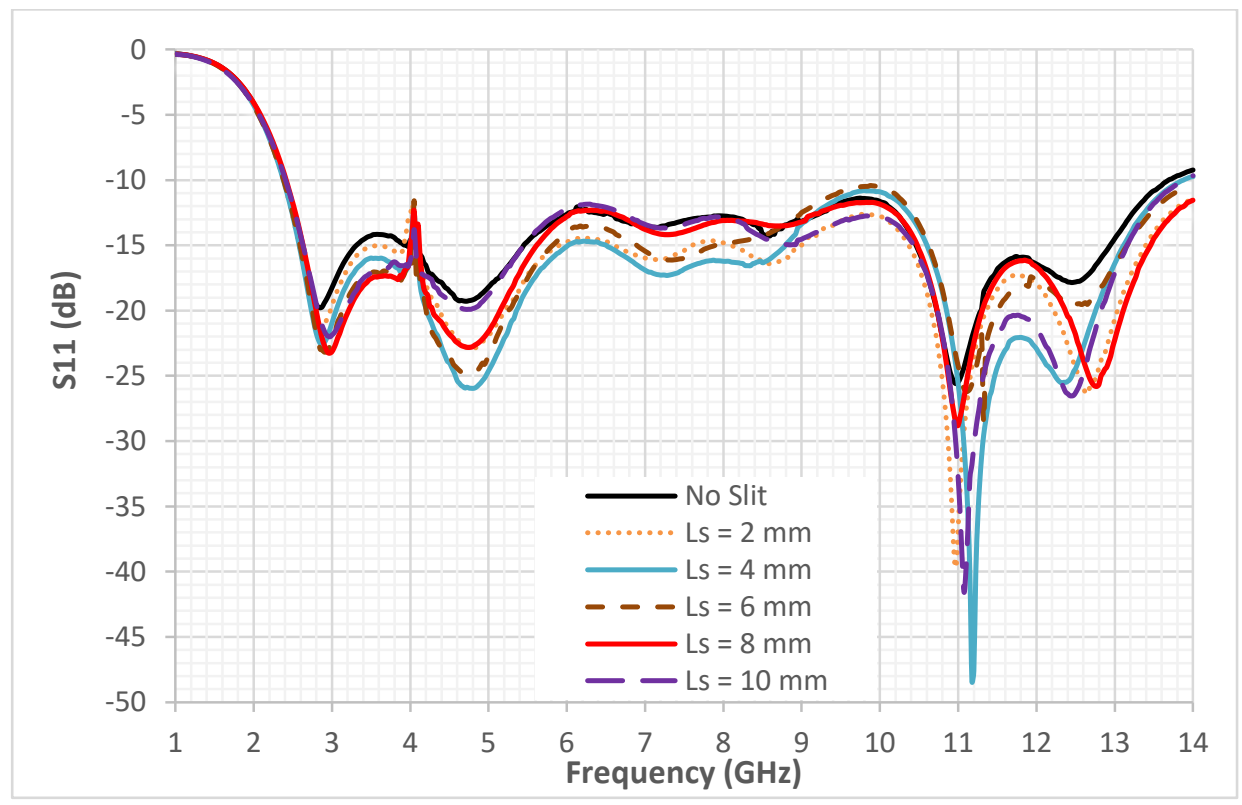

(b)

Fig. 5. Simulated reflection coefficient for different values of rectangular slit dimmensions: (a) $0<W_{S}<3.5 \mathrm{~mm}$ and $L_{S}=6 \mathrm{~mm}$; (a) $0<L_{S}<10.0 \mathrm{~mm}$ and $W_{S}=1.5 \mathrm{~mm}$. 


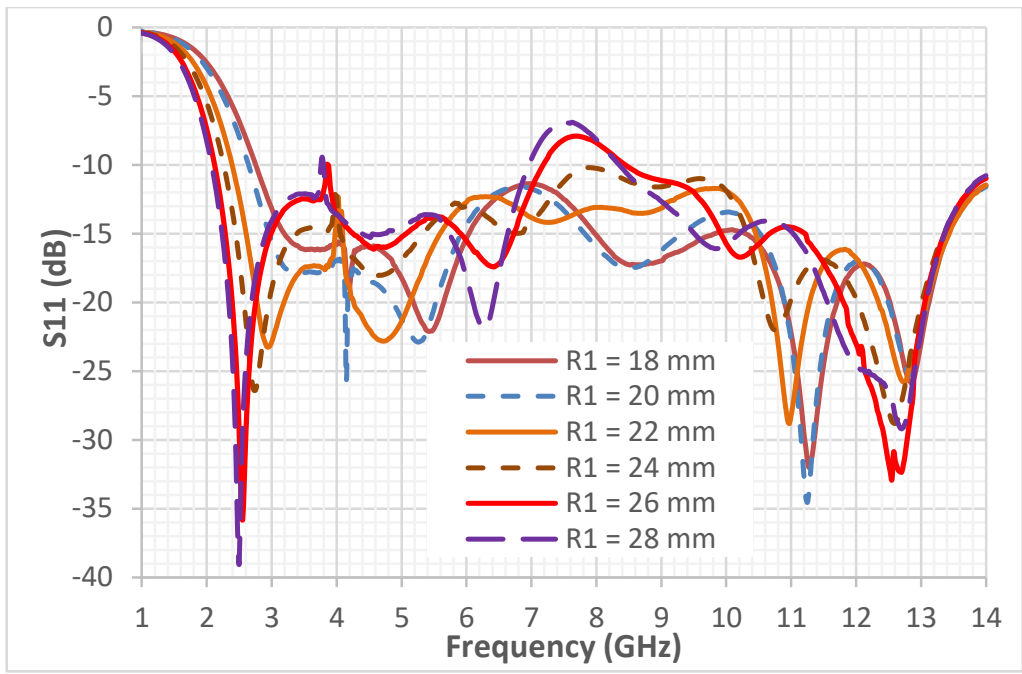

(a)

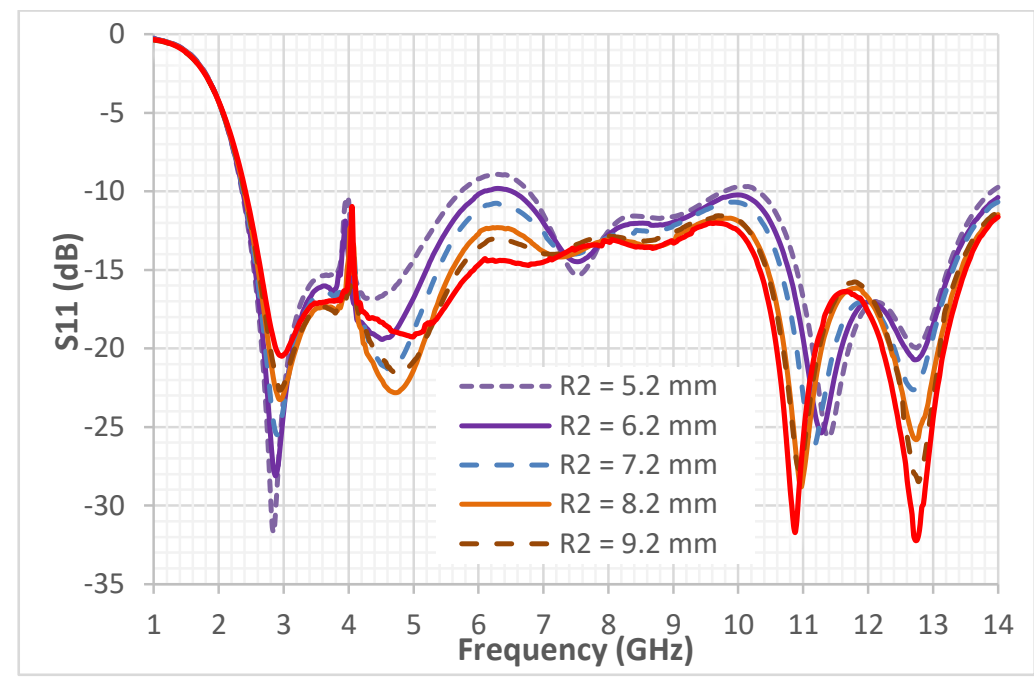

(b)

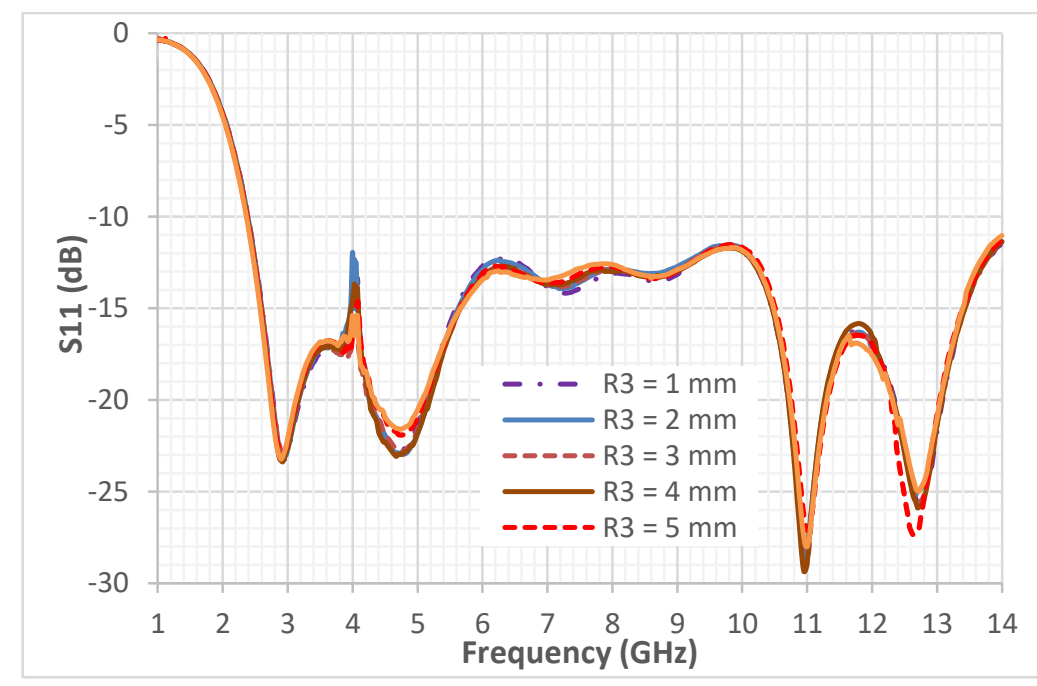

(c)

Fig. 6. Simulated reflection coefficient for different values of: (a) $R_{1}$, (b) $R_{2}$, (c) $R_{3}$. 


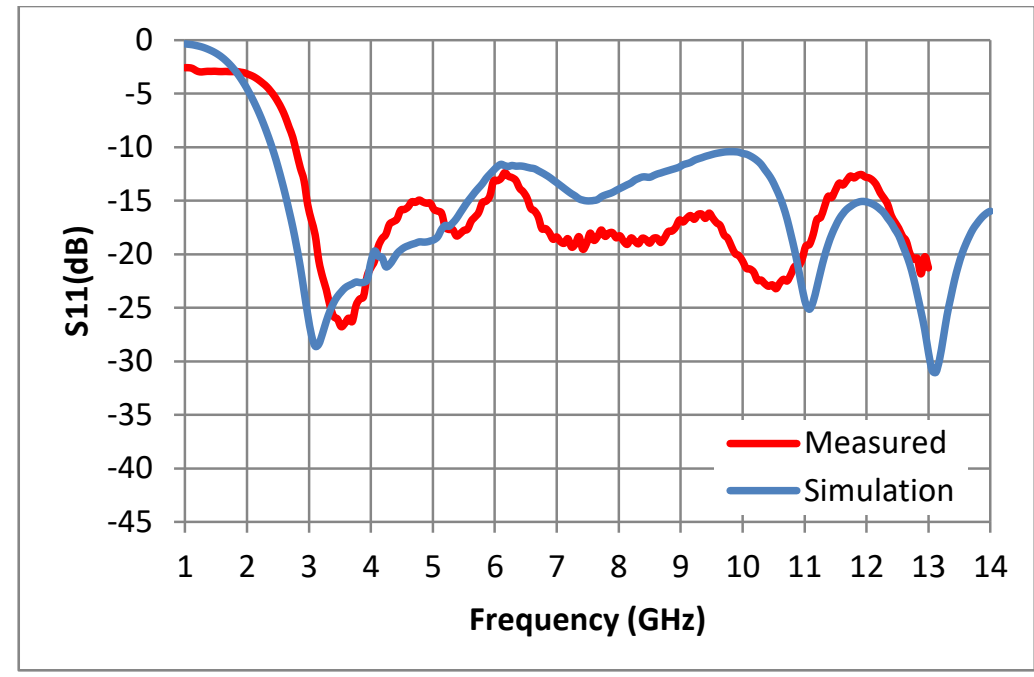

Fig. 7. Measured and simulated results for the return loss.

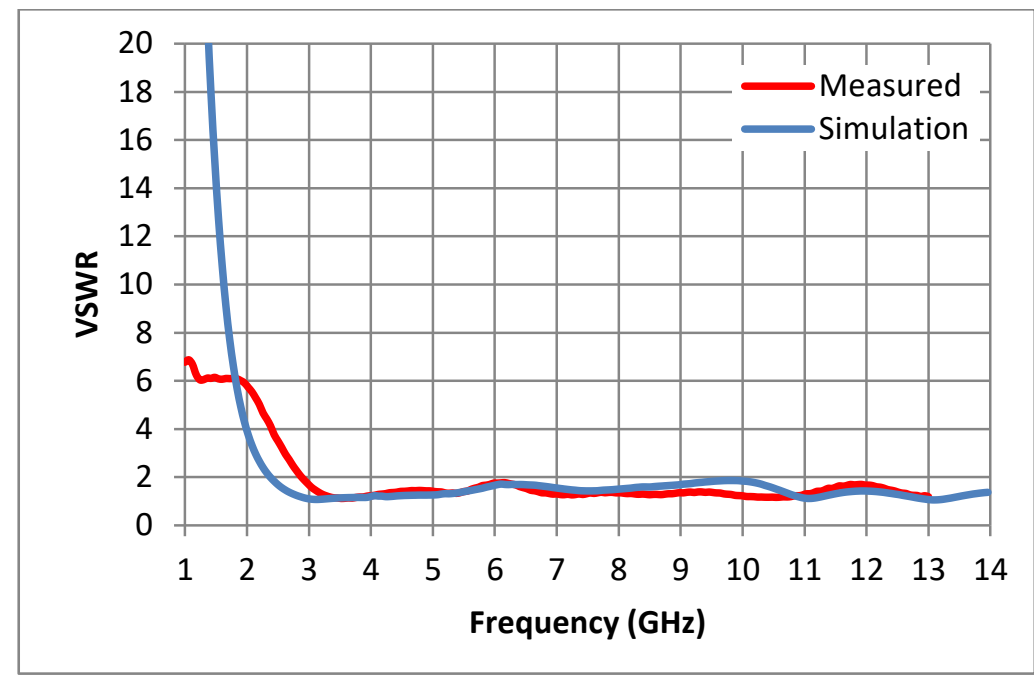

Fig. 8. Measured and simulated results for VSWR.

TABLE 2 - MEASURED AND SIMULATED RESUlTS FOR PROPOSED ANTENNA.

\begin{tabular}{cccc}
\hline & $\mathbf{F}_{\mathbf{1}}(\mathbf{G H z})$ & $\mathbf{F}_{\mathbf{2}}(\mathbf{G H z})$ & $\mathbf{B W}(\mathbf{G H z})$ \\
\hline Simulated & 2.30 & 12.20 & 9.90 \\
\hline Measured & 2.74 & 13.00 & 10.26 \\
\hline
\end{tabular}

Fig. 9 shows antenna impedance plots on Smith chart obtained from simulation, Fig. 9(a), and measurement, Fig 9(b), in the 2.5-3.5 GHz band. The best measured result for $50 \Omega$ impedance matching occurs at $3.5 \mathrm{GHz}$. Fig. 10 shows the directive gain patterns and electric current distributions for the frequencies 3.2, 6.2 and $10.1 \mathrm{GHz}$, respectively. It can be seen by Fig. 13 that the UWB Inga marginata leaf-shaped antenna has directive gain patterns similar to a dipole antenna. This is due to the truncated ground plane, thus allowing the possibility of being applied to various portable communication devices. Figs. 10(b), 10(d) and 10(e) show simulated electric current density 

DOI: http://dx.doi.org/10.1590/2179-10742017v16i1891

distributions. Higher current densities are notice on microstrip feedline, ground plane slitted-edge and leaf-shaped edges.

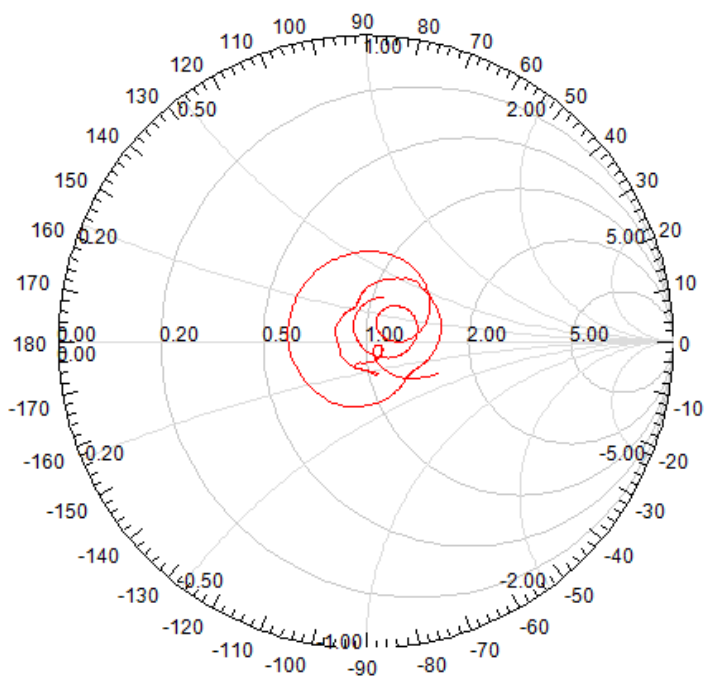

(a)

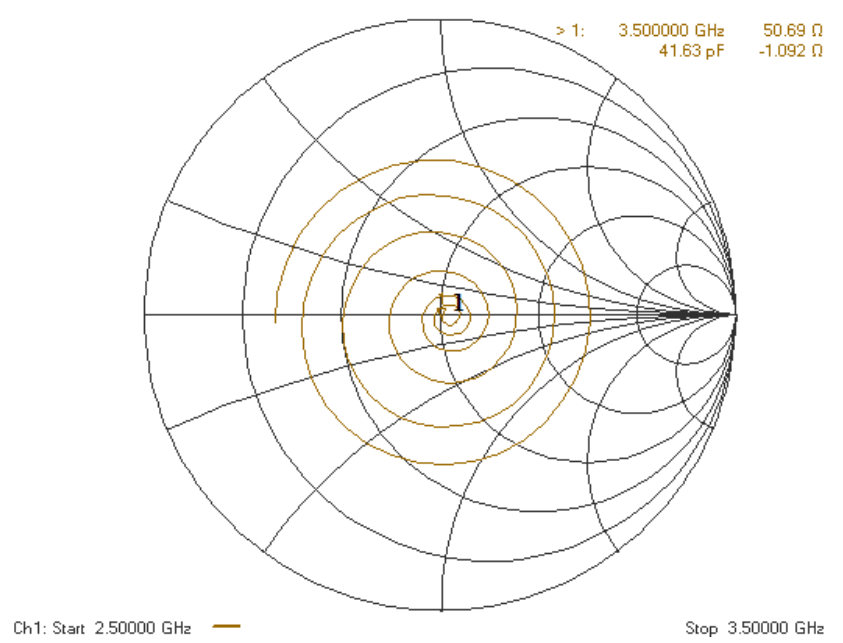

(b)

Fig. 9. Antenna impedance plots on Smith chart: (a) simulated; (b) measured. 


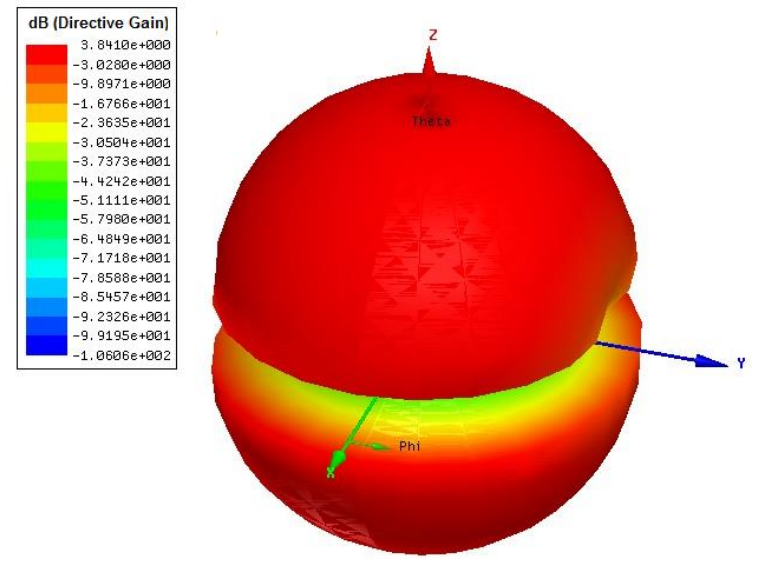

(a)
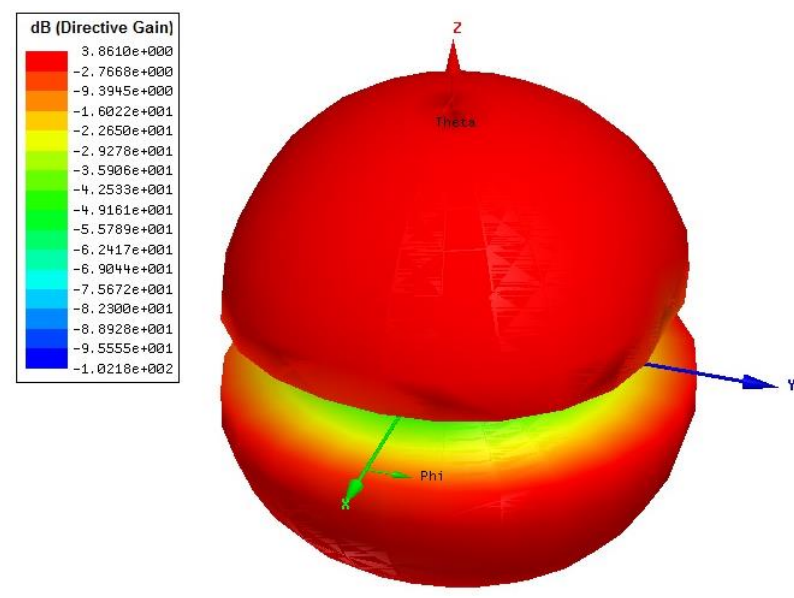

(c)

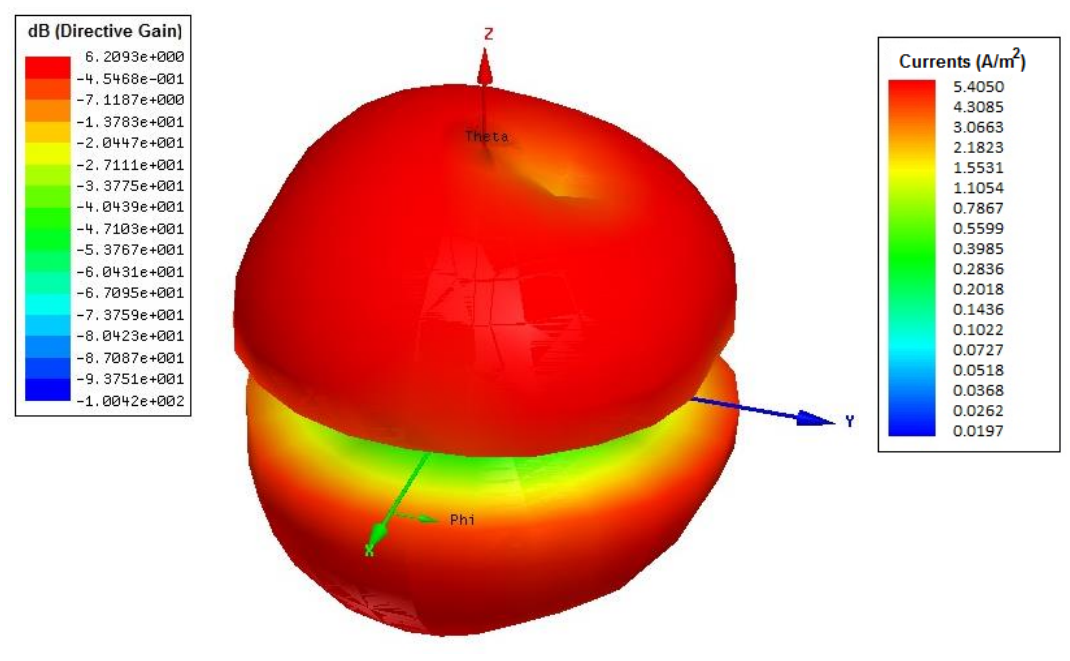

(e)

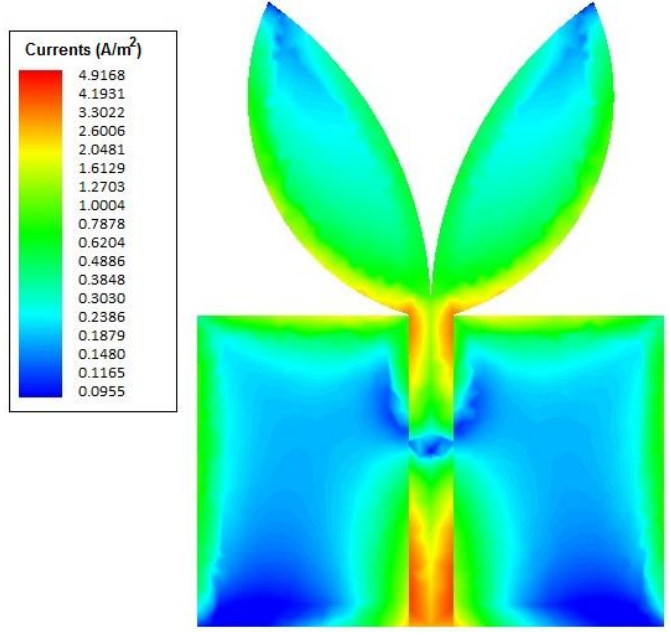

(b)
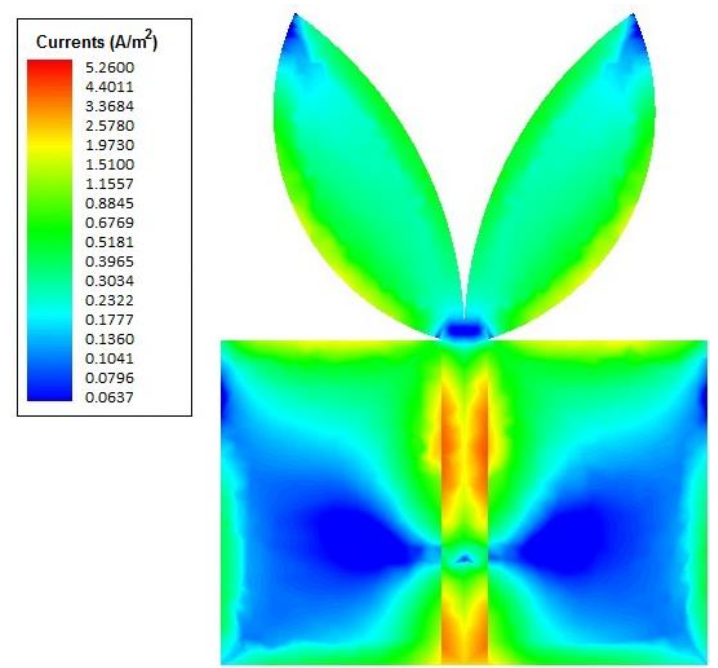

(d)

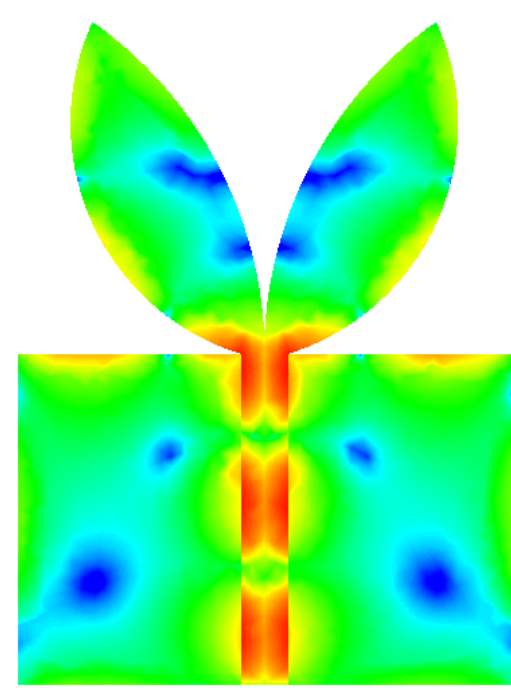

(f)

Fig. 10. 3-D directive gain patterns for the frequency of (a) $3.2 \mathrm{GHz}$, (c) $6.2 \mathrm{GHz}$ and (e) $10.1 \mathrm{GHz}$ and respective electric current density distributions (b), (d) and (f). 


\section{CONCLUSIONS}

A parametric study and experimental verification of proposed microstrip leaf-shaped PMA bioinspired on Inga marginata leaf was presented in this paper for UWB applications. The resonant behavior of the proposed antenna with variation of its main dimensions was analyzed. The experimental results indicate a bandwidth higher than $10.26 \mathrm{GHz}$, superior to the required UWB band, which accredits the proposed antenna to applications in UWB systems. Simulated radiation patterns, impedance on Smith chart and distribution of current density for the proposed PMA were presented and analyzed. Simulated and measured results for return loss and VSWR are in consonance. Thus, considering the simplicity, compact structure, low cost and the consistent results, the proposed Inga marginata leaf-shaped printed monopole antenna appears to be quite efficient and with potential for UWB applications.

\section{ACKNOWLEDGMENTS}

The authors would like to thank CNPq, CAPES, NAMITEC and GTEMA-IFPB the support in research.

\section{REFERENCES}

[1] A. A. L. Leyestanak, "Ultra wideband rose leaf microstrip patch antenna". Progress In Electromagnetics Research, PIER 86, 155-168, 2008.

[2] O. Haraz and A. R. Sebak, "UWB antennas for Wirelles applications”. INTEC, pp. 125-152, 2013.

[3] P. F. S. Junior, "Projeto de antenas bioinspiradas em plantas para sistemas de comunicação sem fio". Master's thesis, IFPB, João Pessoa, 2015.

[4] M. E. Ghavami, R. Michael and L. B. Kohno, "Ultra Wideband Signals and Systems in Communication Enginnering". $2^{\text {nd }}$ ed. (S.1.): JonhWiley\& Sons Ltd, 2007.

[5] D. R. Melo, “Antenas Compactas de Microondas de Banda Larga e Banda Ultra-Larga (UWB)". Doctoral Dissertation in Electrical Engineering, Federal University of Pará, Belém, 2011.

[6] C. A. Balanis, “Teoria de Antenas”. Vol. 2 Transl. by: J. R. Souza. Ri de Janeiro: LTC, 2009.

[7] C. L. Heringer, "Desempenho e Complexidade de Sistemas DS-UWB em Canais Multipercursos Densos". Master's thesis, University of Londrina, Center of Technology and Urbanism, Department of Electrical Engineering. Londrina, 2007.

[8] N. Z. Chen and M. Y. W. Chia, "Broadband Planar Antennas: Design and Applications". Chichester: Wiley, 2006. 243 p.

[9] L. X. Bao, M. J. Ammana, "Investigation on UWB printed monopole antenna with rectangular slitted ground plane". Microwave Opt. Technol. Lett., v.49, p.1578-1585, Jul. 2007.

[10] O. M. H. Ahmed, A. R. Sebak, "A novel maple-leaf shaped UWB antenna with a 5.0-6.0 GHz band-notch characteristic." Progress In Electromagnetics Research, vol. 11, 2009.

[11] Inga Marginata Wild. Disponível em: flora.ipe.org.br/sp/146?pdf=1. Acesso em: 12 Jan. 2016.

[12] T. Pickering, G. Wyatt, "Inga marginata, leaves". Disponível em: www.discoverlife.org/mp/20p?see=I_BC1493\&res=640. Acesso em: 12 Jan. 2016.

[13] http://www.ansys.com 